\title{
MiR-148b, MiR-152/ALCAM Axis Regulates the Proliferation and Invasion of Pituitary Adenomas Cells
}

\author{
Wei He Ling Huang Min Li Yue Yang Zhen Chen Xiaoli Shen \\ Department of Neurosurgery, the Second Affiliated Hospital of Nanchang University, Nanchang, China
}

\section{Key Words}

Mir-148b $\cdot \operatorname{miR}-152 \cdot$ ALCAM $\cdot$ Pituitary Adenomas

\begin{abstract}
Background/Aims: Aberrant expression of miRNA has been found in many tumor tissues to regulate the tumorigenesis by binding to the $3^{\prime}$ - untranslated region ( $3^{\prime}-U T R$ ) of the target genes. The aim of this study is to investigate the role of miR-148b, miR-152/ALCAM axis in human pituitary adenomas (PAs). Methods: First, we detected the expression level of miR148b-3p and miR-152 in human PAs samples by using qRT-PCR. Then we studied the role of miR-148b-3p, miR-152 on human PAs cell proliferation, invasion and apoptosis by using MTS assay, Transwell invasion assay and Annexin V/PI Staining Test. To study the relationship between miR-148b-3p, miR-152 and activated leukocyte antigen molecule (ALCAM), we overexpressed miR-148-3p or miR-152 by transfecting specific mimics. Lucifearase reporter assay was then performed to confirm the target. Next, we studied the biological functions of ALCAM in human PAs cells. Finally, the role of miR-148b-3p, miR-152/ALCAM axis in PAs cells was studied. Results: The expression level of miR-148-3p and miR-152 in invasive PAs samples was lower than those in noninvasive samples. Overexpression of miR-148b-3p, miR152 could repress proliferation and invasion, and promote apoptosis. Moreover, miR-148b$3 p$ and miR-152 could repress activated leukocyte antigen molecule (ALCAM) expression. Knockdown of ALCAM could repress proliferation and invasion and promote apoptosis. By contrary, overexpression of ALCAM promoted proliferation and invasion. Further, the rescue experiments indicated that overexpression of ALCAM significantly restored the proliferation, apoptosis, and invasion influenced by miR-148b-3p and miR-152. Conclusions: Our study suggests that miR-148b-3p, miR-152 may serve as suppressors in PAs through downregulating ALCAM expression. miR-148b, miR-152/ ALCAM axis may be a new therapeutic target in the future.
\end{abstract}

(C) 2017 The Author(s)

Published by S. Karger AG, Basel

\section{Introduction}

In recent meta-analysis, pituitary adenomas occurred with frequency of $14.4 \%$ (range: 1-35\%) and 22.5\% (range: 1-40\%) in pooled autopsy and radiological series, respectively

W. He and L. Huang contributed equally to this work. 
[1]. These figures indicate that pituitary adenomas (PAs) are fairly common in the general population. The pituitary gland tissue is in close proximity to the brain, which means the invasive adenomas may invade into the cranial bone, sphenoid bone, or dura mater [2]. These aggressive behaviors are due to genetic and epigenetic regulation, hormone excess or insufficiency [3], which suggested the imbalance of related regulatory genes was the potential risk of the tumorigenesis. These also make the early diagnosis and treatment be of great importance for the patients, prevent the appearance of visual defects, endocrine disorders and other symptoms [4]. Because of the limitation of access to human tissue, lack of human cell lines and lack of animal models [5], the molecular mechanism of tumorigenesis and development are still unclear. Additionally, few markers have been identified to reliably predict the behavior of PAs. It is also urgent to find out a biomarker which is able to improve clinical management.

MicroRNAs (miRNAs) are endogenously expressed short noncoding RNAs. miRNAs can bind to 3'-untranslated region (3'-UTR) of target mRNA and result in the mRNA degradation or translational repression to regulate many physiological processes, such as embryonic development, disease occurrence, tissue regeneration and so on [6-10]. Bioinformatics has estimated that miRNAs may regulate $50 \%$ of all human genes, and each miRNA can control hundreds of gene targets [11]. Increasing number of studies suggested that miRNAs affect the progression, pathogenesis, diagnosis, and prognosis of cancer [12]. miRNA was critically involved in the proliferation and invasion progress in many kinds of tumor, such as gastric cancer, pancreatic cancer, breast cancer and colorectal cancer [13-16], while there's still not enough public research about how miRNA affect the proliferation and invasion of PAs.

miR-148b and miR-152 are members of the miR-148/152 family, which have been found to play an important role in regulating proliferation, differentiation, and apoptosis in various tissues such as tumor, non-tumor and normal tissues [17]. The miR-148/152 family worked as a suppressor in many kinds of cancer [18-20]. Altered expression of miR-152 in ovarian is related to cell proliferation [21]. In breast cancer, overexpression of miR-152 repressed cell proliferation by targeting IGF-1R and IRS1 to suppress AKT and MAPK signaling pathways [20]. Lower expression of miR-148b was positively associated with high tumor stage of non-small-cell lung cancer [22]. In cervical cancer, miR-148b significantly decreased the cell proliferation, invasion ability, and induced apoptosis [23].These studies suggested the critical role of miR-152 and miR-148b in regulating the tumorigenesis. However, whether miR-148b and miR-152 can modulate PAs tumorigenesis or further development and the deeper regulatory mechanism still remains largely unknown.

Activated leukocyte cell adhesion molecule (ALCAM) is a transmembrane protein of immunoglobulin superfamily [24], an identified ligand of CD6.ALCAM was found to play an important role in human malignant melanoma progression and formation of loco-regional and long distant metastases. High ALCAM expression indicates a more invasive phenotype of melanoma cells [25]. Similar to other coding genes, ALCAM works as the downstream target gene of miRNAs. Previous studies showed that ALCAM is regulated by miR-9, miR-483-5p and miR-126-5p and always relevant to invasive behavior in different tumors [26-28]. While, if ALCAM regulates the proliferation and invasion capacity of PAs cells and is regulated by miRNAs still remains unknown.

In this study, we found two miRNAs, miR-148b-3p and miR-152 were significantly downregulated in human PAs invasive tissues compared with noninvasive ones and also in PAs cells lines GH3 and MMQ compared with normal pituitary cells. Overexpression of miR-148b$3 p$, miR-152 could repress proliferation and invasion significantly and promotes apoptosis. miR-148b-3p and miR-152 could target the ALCAM mRNA 3'UTR. Overexpression of ALCAM promoted proliferation and invasion. Rescue experiments indicated that overexpression of ALCAM significantly restored the proliferation, apoptosis, and invasion regulated by miR148b-3p or miR-152.In conclusion, we determined the function of miR-148b-3p, miR-152/ ALCAM signaling pathway in regulating the proliferation and invasion, and providing a potential insight into further therapeutic targets or early diagnosing biomarkers of PAs. 


\section{Cellular Physiology Cell Physiol Biochem 2017;44:792-803 \begin{tabular}{l|l} 
and Biochemistry Published online. November 24, 2017 & $\begin{array}{l}\text { (c) } 2017 \text { The Author(s). Published by S. Karger AG, Basel } \\
\text { www.karger.com/cpb }\end{array}$
\end{tabular} \\ He et al.: MiR-148b, miR-152/AICAM Axis in Pituitary Adenomas}

\section{Materials and Methods}

\section{Cell culture and human tissue samples}

Rat PAs cell lines GH3, MMQ were used in this research and obtained from the American Type Culture Collection. GH3 cells were cultured in high-glucose DMEM (Sigma), supplemented with 10\% (v/v) fetal calf serum (FCS) (Sigma), $100 \mathrm{U} / \mathrm{ml}$ penicillin and $100 \mu \mathrm{g} / \mathrm{ml}$ streptomycin sulfate (Sigma). MMQ cells were maintained in DMEM containing 15\% horse serum, 2.5\% FBS, $5 \mathrm{U} / \mathrm{ml}$ penicillin and $5 \mathrm{~g} / \mathrm{ml}$ streptomycin. All the cells were incubated at $37^{\circ} \mathrm{C}$ in $5 \% \mathrm{CO} 2$ atmosphere. For obtaining the pituitary cell, we removed the whole brain from the skull and left the pituitary gland in the hypophyseal fossa which can be picked out by tweezer. Pituitary gland was digested by gentle trypsinization. Pituitary cells were suspended in M199 medium with 10\% FBS and cultured in Petri dishes $37{ }^{\circ} \mathrm{C}$ in a humidified atmosphere of $5 \%$ CO2 [29]. Human tissue samples were obtained from the Department of Neurosurgery, the Second Affiliated Hospital of Nanchang University. We collected 10 invasive PA samples and 10 noninvasive PA samples. Informed consent for the research was obtained before the biopsy. Pathologists and radiologists assisted us to distinguish invasive samples from noninvasive samples.

\section{Luciferase reporter vector and transfection}

The 3 '-UTR segment of wild-type ALCAM mRNA, which possessed the binding site for miR-148b-3p, miR-152, was amplified from the MMQ DNA and cloned into the pGL3 vector. The sequences of primers are as follows: PF: 5'-GGCGTCGACAAGACAGCAACAGGCAAGAAAG AGC-3' (Sal1 enzyme); PR:5'-GGCTCTAG ATCGCTTCCTTCTTGTCTTCTTGTCT-3' (Xbal enzyme). The mutant miRNA-binding sites were obtained by replacing the miRNA- binding site sequence with miRNA seed sequences using the QuickChange Lightning Multi Site-Directed Mutagenesis Kit (Agilent Technologies, Santa Clara, CA, USA). The ALCAM expression vector was performed by cloning ALCAM-coding sequence into Fugw. The miR-148b-3p, miR-152 mimics, mimics control, inhibitor, and inhibitor control was purchased from Ribobio (Guangzhou, China) and was transfected into the cell by Lipofectamine 2000 (Thermo, USA).

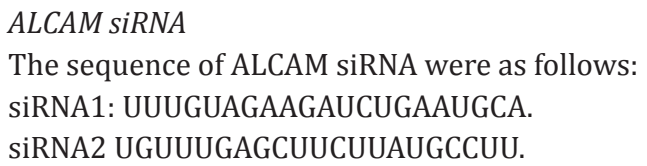

\section{ALCAM overexpression vector construction}

Total RNA was isolated from GH3 cells for synthesizing cDNA by reverse transcription-PCR Kit (TIANGEN). The CDS sequence of ALCAM was amplified by primers as follows into the Fugw vector. So the miRNA cannot repress the protein translation of ALCAM. PF 5'-GGCGGATCCATGGCATCTAAAGGGTCCCC-3' (BamH1 site), PR 5'-GGCGAATTCTTAGGCTTCTGTTTTGTGATTGTTT-3' (EcoR1 site). The vector was transfected into cells for overexpression by Lipofectamine 2000 (Thermo) as the instruction.

\section{Cell counting}

We cultured the cells in the 6 well cell culture clusters. For cells counting, we made the cell suspension and used the Countstar cell count meter (Inno-Alliance Biotech, USA) to count the cell number per milliliter. Then we worked out the whole cell number in each well of different treated group. In the figures, we showed the statistics of the whole cells number in different groups.

Cell proliferation analysis

Cells were seeded in 96-well plates at a density of $3.5 \times 103$ cells/well. Each well was utilized to perform the 3-(4, 5-dimethylthiazol-2-yl)- 5-(3-carboxymethoxyphenyl) -2-(4-sul-fophenyl)-2H-tetrazolium (MTS) proliferation assay following the instruction of CellTiter 96 AQueous One Solution Cell Proliferation Assay (Promega, USA). The $490 \mathrm{~nm}$ absorption value was detected by a spectrophotometer.

Cell invasion assay

Cell invasion assay was carried out in 24-well plates, using transwell inserted with $8.0 \mu$ m pores (Corning 3422). Every transwell was coated with matrigel (BD Bioscience; $50 \mathrm{mg} / \mathrm{mL}$ ) at $37^{\circ} \mathrm{C}$ for more 


\section{Cellular Physiology Cell Physiol Biochem 2017;44:792-803 \begin{tabular}{l|l|l} 
and Biochemistry 10.1159/000485342 & $\begin{array}{l}\text { (c) 2017 The Author(s). Published by S. Karger AG, Basel } \\
\text { www.karger.com/cpb }\end{array}$
\end{tabular} \\ He et al.: MiR-148b, miR-152/AICAM Axis in Pituitary Adenomas}

than $12 \mathrm{~h}$. Cells were seeded in the upper chambers where the medium is serum-free, while the medium in lower chambers contains 10\% FBS. After incubated for about 15 h, 4\% PFA was added into the transwell for $10 \mathrm{~min}$. Cells were stained with Hoechst 33342 avoid light for $5 \mathrm{~min}$ and then washed 3 times with PBS. At last, 24-well plates should be observed under a fluorescence microscope to count the number of cells. We performed 3 independent experiments and chose more than 5 random fields of cells in each group for statistics.

\section{Cell apoptosis analysis}

Apoptosis rates were evaluated by flow cytometry (FACS Calibur, USA) by Apoptosis and Necrosis Assay Kit (Beyotime, China). According to the instruction of the kit, 195 $\mu$ l Annexin V-FITC combination solution was added to cell suspension. Then $5 \mu$ l Annexin V-FITC and $10 \mu$ propidium iodide were added to the solution and incubated for $20 \mathrm{~min}$ at the room temperature. After the incubation, cells were put on the ice for FACS detection.

\section{Quantitative real- time PCR ( $q R T$ - PCR)}

miRNA qRT-PCR

The total RNA was isolated using RNAiso (Takara, Dalian, China). miRNA was subsequently reversetranscribed to cDNA using the miRNA-specific stem-loop reverse-transcription primer (Ribobio, Guangzhou, China). The amount of target gene expression $\left(2^{-\Delta \Delta C t}\right)$ was normalized via the endogenous small nuclear RNA U6 using miRNA-specific primers (Ribobio). The reaction conditions were performed according to the instructions from Ribobio Co., Ltd with SYBR Green qPCR Mix (BioRad, Hercules, CA).

mRNA qRT-PCR

cDNA was subsequently reverse-transcribed from mRNA by M-MLV Reverse Transcriptase (Takara). The PCR included 40 cycles of amplification using the Stratagene Mx3000P system with SYBR Green qPCR Mix (BioRad, Hercules, California). Expression of target genes $\left(2^{-\Delta \Delta C t}\right)$ was normalized to GAPDH.

The primer sequences are as follows:

ALCAM: PF 5'-ACTTGACGTACCTCAGAATCTCA-3', PR 5'- CATCGTCGTACTGCACACTTT -3'

GAPDH: PF 5'- CTGGGCTACACTGAGCACC-3', PR 5'- AAGTGGTCGTTGAGGGCAATG-3'.

Western blotting and antibodies

Cells were lysed with $1 \times$ SDS- PAGE loading buffer and then transferred onto PVDF membranes (Millipore). Antibodies used "in this study were listed as follows: anti-GAPDH (ab97626, Abcam, Cambridge, MA, USA), anti-ALCAM (ab109215, Abcam, Cambridge, MA, USA). The antibodies dilutions were 1:2000. Signals were detected by enhanced chemiluminescence (ECL) (Thermo, USA). The image intensity of western blot was worked out by using Image J software.

Luciferase reporter assay

For prediction of the miRNAs target, we used the online tool of "Miranda" http://www.microrna.org/ microrna/home.do. and "targetscan" http://www.targetscan.org/vert_71/. Cells were seeded in 24-well plates at a density of $5 \times 10^{5}$ cells/ well, co-transfected with modified firefly luciferase vectors and miR148b-3p, miR-152 or control miRNAs mimics (Biotend, Shanghai, China) oligonucleotides. After $48 \mathrm{~h}$ of transfection, the cells were harvested and lysed. The activity of firefly luciferase was detected according to the instruction of the dual-luciferase assay system (Promega, Madison, WI, USA).

Hormone assays

Growth Hormone (GH) and Prolactin (PRL) concentrations in culture were measured using GH ELISA kit (CSB-E07342r, Cusabio, USA) and PRL ELISA kits (CSB-E06881r, Cusabio, USA), respectively.

\section{Statistical analysis}

Student's t-test, one-way ANOVA, and Mann-whitney test were used to test the significance of differences. The results were considered statistically significant when $\mathrm{P}$ values were $<0.05$. All $\mathrm{P}$ values were indicated in the figures. 


\section{Cellular Physiology Cell Physiol Biochem 2017;44:792-803 and BiOChemistry \begin{tabular}{l|l} 
DOI: 10.1159/000485342 & $\begin{array}{l}\text { C } 2017 \text { The Author(s). Published by S. Karger AG, Basel } \\
\text { www.karger.com/cpb }\end{array}$
\end{tabular} \\ He et al.: MiR-148b, miR-152/AICAM Axis in Pituitary Adenomas}

\section{Results}

miR-148b-3p, miR-152 represses the proliferation and invasion of PAs cells

We detected that the expression level of miR-148b-3p, miR-152 was lower in invasive pituitary adenoma patient cancer samples $(n=10)$ than noninvasive ones $(n=10)$ (Fig. 1A). We hypothesized that miR-148b-3p, miR-152 may be the potential biomarkers for indicating the grade malignancy of PA or regulators of tumorigenesis. Then we found that the miR-148b3p, miR-152 expression level of PAs cell lines, GH3 and MMQ, were significantly decreased compared with normal rat pituitary cells (Fig. 1B). Then we transfected the miR-148b-3p and miR-152 mimics and detected the overexpression effect (Fig. 1C) in GH3 cells. We found that the decreased cell number was detected after the overexpression of miR-148b-3p and miR-152 (Fig. 1D). Further experiment showed that the proliferation was inhibited by overexpressing miR-148b-3p, miR-152 (Fig. 1E), whereas the apoptosis rate was increased at the same time in GH3 cells (Fig. 1F) and also in MMQ cells (for all online suppl. material, see www.karger.com/doi/10.1159/000485342, Fig. S1A and S1B). Transwell invasion assay showed that overexpression of miR-148b-3p and miR-152 inhibited cells invasion ability in both GH3 cells (Fig.1G) and MMQ cells (see supplementary material, Fig. S1C). Transfection of miR-148b-3p inhibitor or miR-152 inhibitor which is the antisense nucleic acid of the miRNAs to repress the function of miRNAs in GH3 cells induced the increase of cell number (Fig. 1H) and proliferation (Fig. 1I). The apoptosis was also decreased by transfection of miRNA inhibitor respectively (Fig. 1J). Additionally, the invasion ability was also promoted by transfection of miRNA inhibitor (Fig. 1K). Since GH and PRL were the hormones secreted by PAs. PA patients were troubled by the disordered secretion of the hormone. We detected two important hormones GH and PRL mRNA expression in the GH3 cell lines which overexpressed with miRNAs to find the induction of hormone regulation. We found that there's a little downregulation of the mRNA expression of GH, PRL in the cell lines overexpressed with miRNAs. We detected the expression of prolactin (PRL) and growth hormone (GH) mRNA in GH3 cells transfected with miR-152 or miR-148b-3p. There's a little downregulation of prolactin (PRL) and growth hormone (GH) compared with the control group (see supplementary material, Fig. S1D, S1E).

miR-148b-3p, miR-152 downregulates the expression of ALCAM

To validate the influence of the miRNAs on ALCAM expression, we analyzed that overexpression of miR-148b-3p, miR-152 significantly downregulated the expression of ALCAM on both mRNA and protein level (Fig. 2A and 2B). By using bioinformatic tools (Miranda, targetscan) we found the miRNA-targeting sites of miR-148b-3p, miR-152 on the 3 -UTR of ALCAM (Fig. 2C). We performed the luciferase reporter assay and found that miRNAs inhibited the luciferase expression of wild-type ALCAM 3`-UTR. By contrast, when mutant happened at the binding sites, the luciferase level showed no significant difference from the control group (Fig. 2D).

ALCAM is critically involved in the proliferation and invasion of PAs cells

In order to detect the function of ALCAM, we overexpressed ALCAM in GH3 cell line to detect both of the mRNA and protein expression level (Fig. 3A). Then we found that there're more cells in ALCAM overexpression group than in control group during the $72 \mathrm{~h}$ (Fig. 3B). Overexpression of ALCAM promoted GH3 cells proliferation (Fig. 3C). On the other hand, apoptosis was repressed by overexpressing ALCAM (Fig. 3D). Besides, cells invasion was also promoted as a result of the upregulation of ALCAM (Fig. 3E).

Further, we downregulated the expression of ALCAM by transfecting ALCAM-siRNA (Fig. 3F) and found that lower expression of ALCAM resulted in the cell number decreasing compared with control group (Fig. 3G), because of the inhibition of proliferation (Fig.3H) and increasing apoptosis rate in GH3 cells (Fig. 3I) and MMQ cells (see supplementary material, Fig. S2A and S2B). Transwell invasion assay showed that the invasion of PAs cells was suppressed when transfected with ALCAM-siRNA (Fig. 3J and see supplementary material, Fig. S2C). 
Fig. 1. $m i R-148 b-3 p$, miR-152 represses the proliferation and invasion of PAs cells. (A) Expression level of miR-148b, miR-152 in invasive $(\mathrm{n}=10)$ and noninvasive PA patient cancer samples(n=10). ${ }^{*} \mathrm{P}<0.05,{ }^{*} \mathrm{P}<0.01$. (B) qRT-PCR result shows that miR-148b-3p and miR-152 expression was reduced in the rat GH3, MMQ cell lines compared with normal rat pituitary cells. Data shown are means \pm SD $(n=3) .{ }^{*} \mathrm{P}<0.05$, ${ }^{* *} \mathrm{P}<0.01$ versus the corresponding control. (C) Expression level of miRNAs mimics transfected into GH3 cells. Data shown are means \pm SD $(n=3) .{ }^{*} \mathrm{P}<0.05$, ${ }^{* *} \mathrm{P}<0.01$. (D) Reduced cell number caused by overexpression of miRNA respectively in GH3 cells. Data shown are means $\pm S D(n=3)$. ${ }^{*} \mathrm{P}<0.05,{ }^{*} \mathrm{P}<0.01$. (E) MTS proliferation assay showed inhibition of cells proliferation

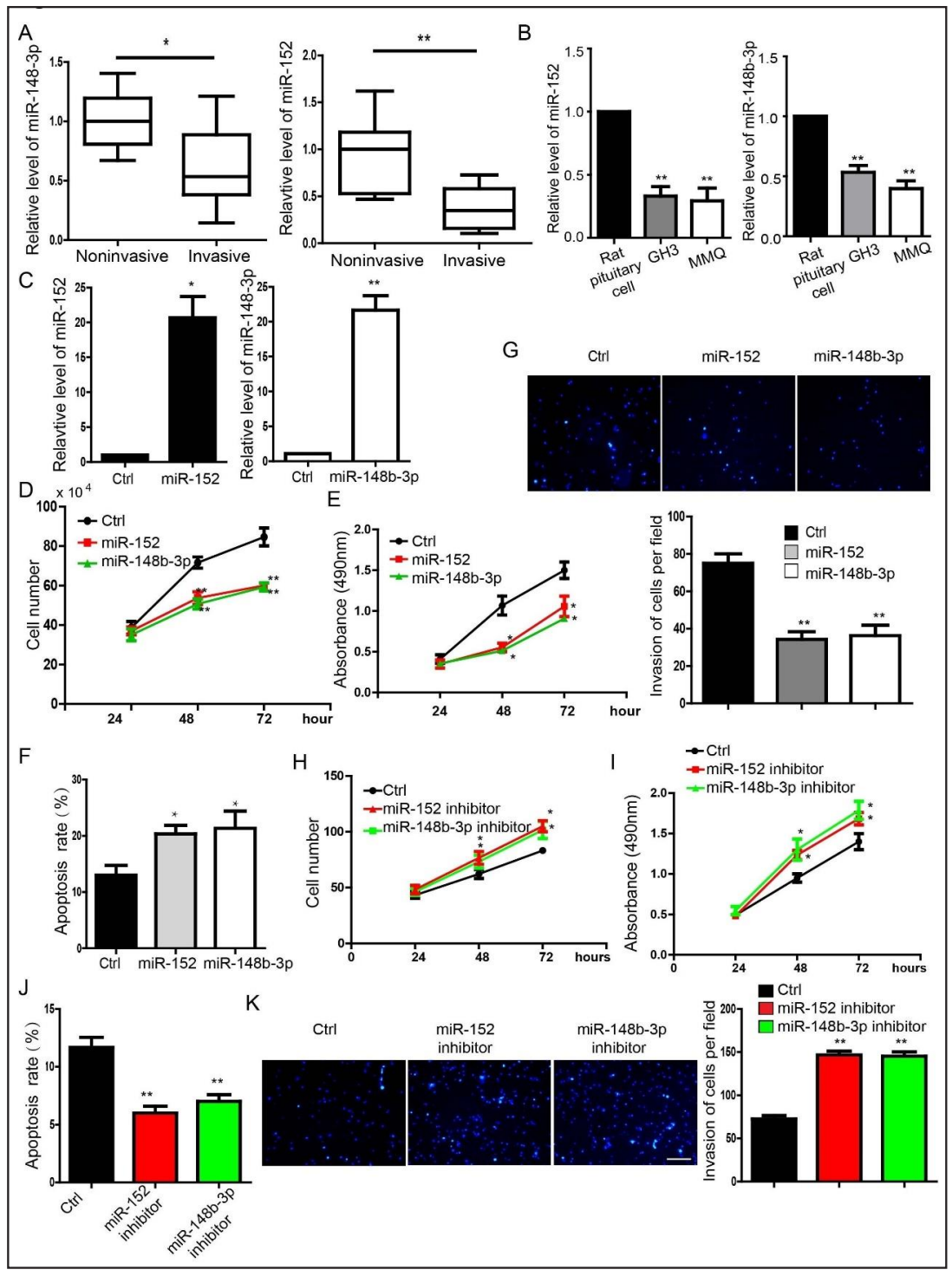
caused by miRNAs. Data shown are means $\pm \mathrm{SD}(\mathrm{n}=3)$. ${ }^{*} \mathrm{P}<0.05$, ${ }^{* *} \mathrm{P}<0.01$. (F) Apoptosis rate increased in GH3 cells overexpressed with miRNAs. Data shown are means $\pm \mathrm{SD}(\mathrm{n}=3) .{ }^{*} \mathrm{P}<0.05$. (G) Transwell assay was performed to measure the invasive capacity of GH3 cells overexpressed with miRNAs. The scale bar represents $100 \mu \mathrm{m}$. The painel below showed the statistics of the invasion. Data shown are means \pm SD (n3). ${ }^{* *} \mathrm{P}<0.01$.(H) Statistics of ell number of GH3 cells transfected with miR-148b-3p inhibitor, miR-152 inhibitor or control. Data shown are means $\pm \mathrm{SD}(\mathrm{n}=5)$. ${ }^{*} \mathrm{P}<0.05$. (I) MTS proliferation assay. Data shown are means \pm $\mathrm{SD}(\mathrm{n}=5) .{ }^{*}<0.05$. (J) Apoptosis was decreased by transfecting the miRNA inhibitor. Data shown are means $\pm \mathrm{SD}(\mathrm{n}=4){ }^{* *} \mathrm{P}<0.01$. (K) miRNAs inhibitor promotes the invasion of GH3 cells. The scale bar represents 100 $\mu \mathrm{m}$. Data shown are means $\pm \mathrm{SD}(\mathrm{n}=3){ }^{* *} \mathrm{P}<0.01$.

\section{ALCAM mediated the influence ofmiR-148b-3p, miR-152 in PAs cells}

To determine whether this two-miRNAs panel promoted cell proliferation and invasion by inhibiting ALCAM expression levels, we carried out rescue experiments by introducing exogenous ALCAM in these miRNAs overexpressed GH3 cells. We detected that overexpression of ALCAM significantly restored the ALCAM level which was repressed by overexpression of miRNAs (Fig. 4A and 4F). Notably, in contrast to the function of overexpression miR-148b$3 p$ or miR-152 respectively, GH3 cell with overexpression of ALCAM showed a significant 
Fig. 2. $m i R-148 b-3 p, m i R-$ 152 downregulates the expression of ALCAM by directly targeting the $3{ }^{`}$-UTR. (A) mRNA level of ALCAM detected by qRT-PCR in the GH3 cells transfected with miR-148b-3p, miR-152 or control miRNA. Data shown are means \pm SD $(n=4)$. ${ }^{*} \mathrm{P}<0.05, \quad * * \mathrm{P}<0.01$. Western blot showed protein level of ALCAM expression was downregulated by miRNAs in GH3 cells. (C) Representation of rat ALCAM 3 -UTR and the relative position of the predicted miRNA-binding sites. (D) Relative luciferase activity in GH3 cells co-transfected with miR-148b-3p, miR-152 or control miRNA and reporter vector. Data shown are means $\pm \mathrm{SD}(\mathrm{n}=3)$. ${ }^{*} \mathrm{P}<0.05$ versus the corresponding control.

Fig. 3. ALCAM modulates proliferation and invasion of GH3 cells. (A) qRT-PCR showed the mRNA upregulation level of ALCAM overexpression vector effect. Data shown are means $\pm \mathrm{SD}$ $(\mathrm{n}=3) . \quad * * \mathrm{P}<0.01$. (B) Overexpression of ALCAM led to the GH3 cell number increase during 72 h. (C) Overexpression of ALCAM promoted the GH3 cell proliferation. Data shown are means \pm SD $(n=5)$.
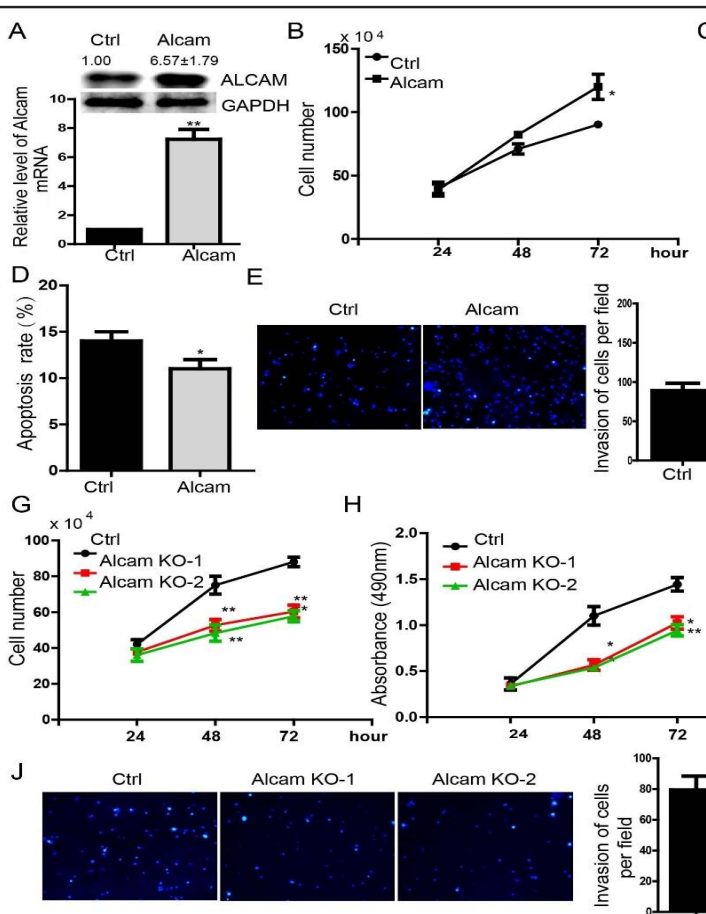

B

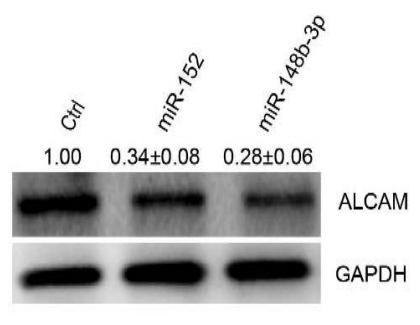

\section{D}

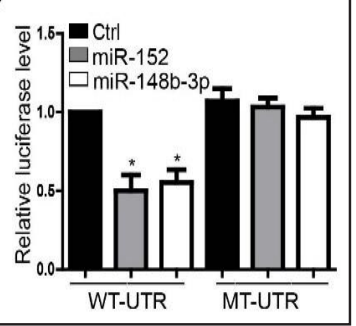
| | | | || || |||

57:5' ucuguaaaUGUC--UGCACUGa 3' Alcam

3'uguuucAAGACACU----ACGUGACu 5' rno-miR-148b-3p | | || | | | | | | || ||

250:5'uuuuuuUUCUGUAAAU GUCUGCACUGa 3' Alcam
3' gguucáagACAGUACGUGACu 5' rno-miR-152

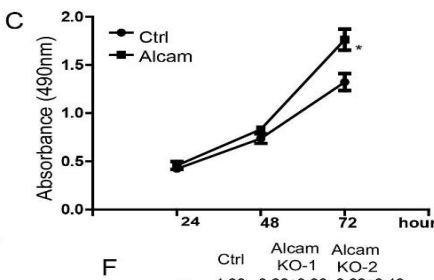

Ctrl Alcam
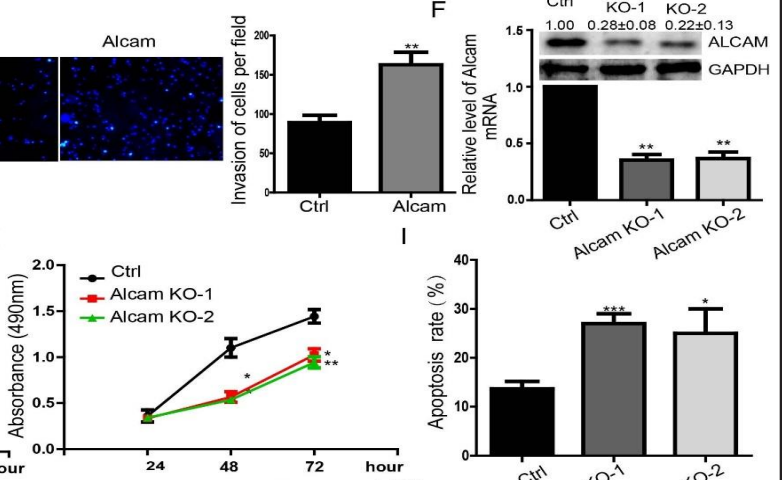

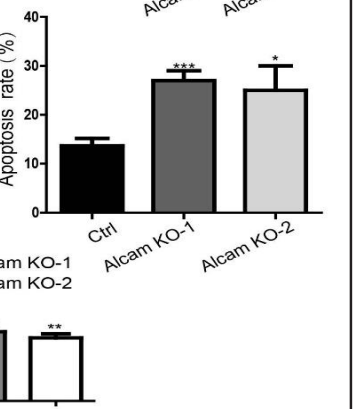

${ }^{*} \mathrm{P}<0.05$. (D) Overexpression of ALCAM inhibited the apoptosis. Data shown are means $\pm \mathrm{SD}(\mathrm{n}=3)$. ${ }^{*} \mathrm{P}<0.05$.

(E) Overexpression of ALCAM promoted the GH3 cell invasion. The scale bar represents $100 \mu \mathrm{m}$. Right painel showed the statistics of the invasion. Data shown are means $\pm \mathrm{SD}(\mathrm{n}=3) .{ }^{* *} \mathrm{P}<0.01$. (F) The mRNA level of ALCAM was reduced by transfected siRNA-ALCAM-1 or siRNA-ALCAM-2 which specially target ALCAM. Data shown are means $\pm \mathrm{SD}(\mathrm{n}=3)$. ${ }^{* *} \mathrm{P}<0.01$. (G) Inhibition of ALCAM led to GH3 cell number a significant decrease and $(\mathrm{H})$ inhibition of proliferation compared with the control group increase of apoptosis rate (I). Data shown are means $\pm \mathrm{SD}(\mathrm{n}=3)$. ${ }^{*} \mathrm{P}<0.05,{ }^{* *} \mathrm{P}<0.01,{ }^{* * *} \mathrm{P}<0.001$. (J) Downregulation of ALCAM obviously repressed GH3 cell invasion. The scale bar represents $100 \mu \mathrm{m}$. Right histogram showed the statistics of the invasion. Data shown are means $\pm \mathrm{SD}(\mathrm{n}=3)$. ${ }^{*} \mathrm{P}<0.05,{ }^{*} \mathrm{P}<0.01$. 
Fig. 4. $A L-$ CAM mediated the influence of miR-148b3p, miR152 in GH3 cells.

(A) The expression of ALCAM MRNA with the treatment of control or ALCAM overexpression in GH3 cell overexpressed with miR152. Data shown are means \pm SD $(n=3)$, $* * * \mathrm{P}<0.001$. (B) Overex-
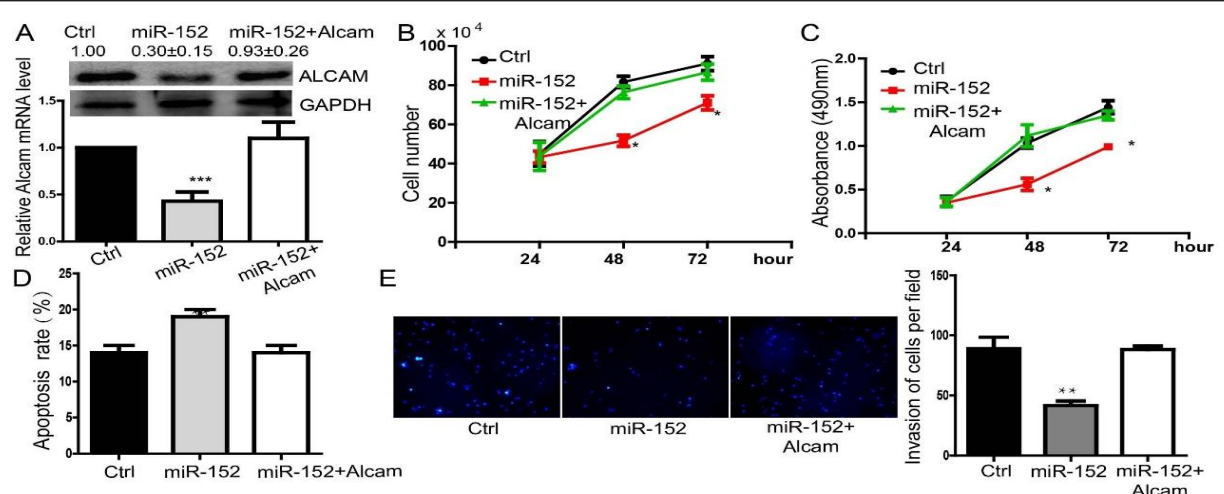
Ctrl miR-148b-3p miR-148b-3p
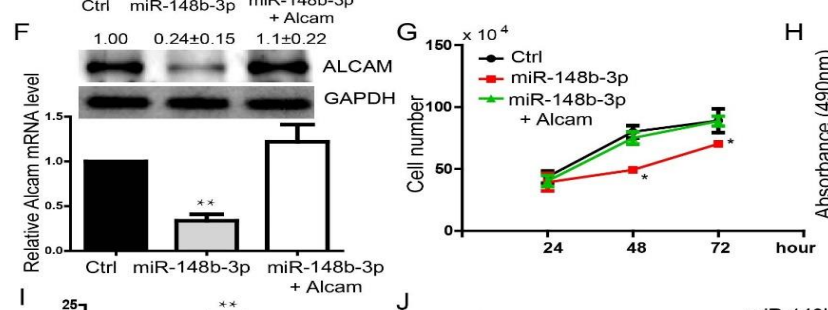

$\left.\mathrm{H} \widehat{E}^{2.0}\right] \rightarrow \mathrm{Ctrl}$
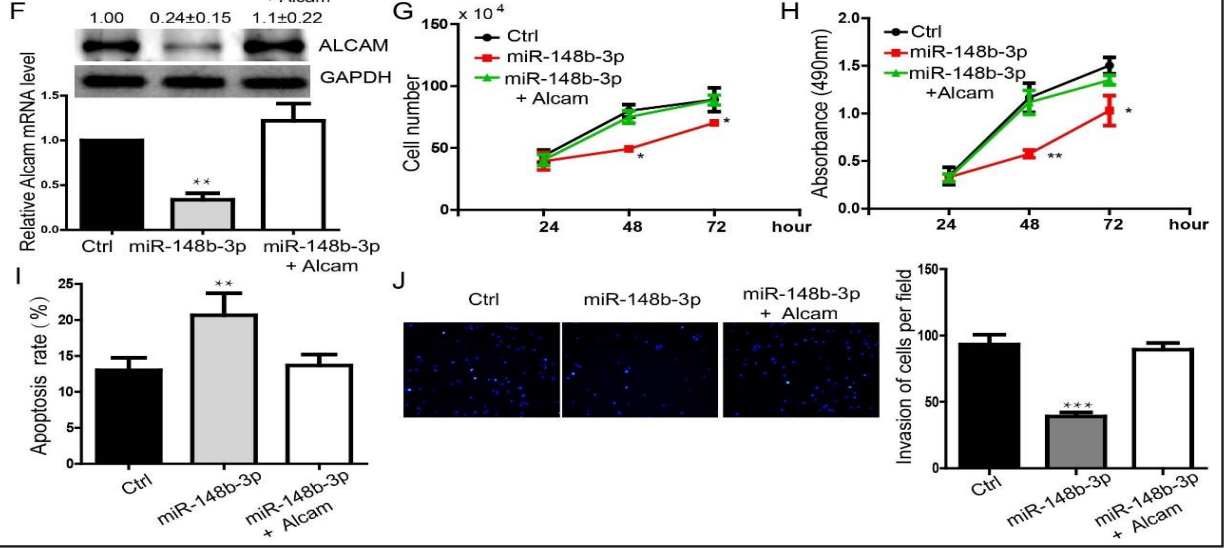

pression of

ALCAM restored the cell number reduced by overexpression of miR-152. Data shown are means \pm SD $(n=3)$, $* \mathrm{P}<0.05$. (C) Overexpression of ALCAM could restore the proliferation repressed by miR-152. Data shown are means $\pm \mathrm{SD}(\mathrm{n}=3),{ }^{*} \mathrm{P}<0.05$. (D) Overexpression of ALCAM could block the function of miR-152 on promoting cell apoptosis. Data shown are means $\pm \mathrm{SD}(\mathrm{n}=3),{ }^{* *} \mathrm{P}<0.01$. (E) Transwell assay showed that ALCAM overexpression could block the invasion inhibition caused by miR-152. The scale bar represents $100 \mu \mathrm{m}$. Right histogram showed the statistics of the invasion. Data shown are means $\pm \mathrm{SD}(\mathrm{n}=3),{ }^{* *} \mathrm{P}<0.01$. (F) The expression of ALCAM mRNA in rescue experiment. Data shown are means $\pm \mathrm{SD}(\mathrm{n}=3),{ }^{* *} \mathrm{P}<0.01$. (G) Overexpression of ALCAM restored the cell number reduced by miR-148b-3p. Data shown are means \pm SD $(n=3)$, ${ }^{*} \mathrm{P}<0.05$. (H) Overexpression of ALCAM could block the repression of proliferation caused by miR-148b-3p. Data shown are means $\pm \mathrm{SD}(\mathrm{n}=3),{ }^{*} \mathrm{P}<0.05$. (I) Overexpression of ALCAM could block the function of miR$148 \mathrm{~b}-3 \mathrm{p}$ on promoting apoptosis. Data shown are means $\pm \mathrm{SD}(\mathrm{n}=3),{ }^{* *} \mathrm{P}<0.01$. (J) Transwell assay showed that ALCAM overexpression could block miR-148b-3p-inhibited cell invasion. The scale bar represents 100 $\mu \mathrm{m}$. Right painel showed the statistics of the invasion. Data shown are means $\pm \mathrm{SD}(\mathrm{n}=3),{ }^{* * *} \mathrm{P}<0.001$.

increase of cell count (Fig. 4B and 4G). Predictably, the overexpression of ALCAM significantly restored the proliferation ability inhibited by overexpressing miRNAs (Fig. 4C and 4H), and the apoptosis was inhibited as well (Fig. 4D and 4I), which were compared with the only miRNAs overexpressing groups. Additionally, the ability of invasion capacity of GH3 cells was restored by overexpression of ALCAM in the cells overexpressed with miR-148b-3p and miR-152, respectively (Fig. 4E and J).

In MMQ cells, the overexpression of ALCAM noticeably restored the proliferation ability which was repressed by overexpressing miR-148b-3p and miR-152 (see supplementary material, Fig. S3A and 3B). Overexpressing ALCAM also release the influence on promoting apoptosis rate caused by overexpression of miRNAs (see supplementary material, Fig. S3C and S3D). At the same time, the function of miRNAs in repressing invasion was blocked when overexpressing ALCAM (see supplementary material, Fig. S3E and 3F). 


\section{Discussion}

In this study, we found that the miR-148b-3p and miR-152 could affect the proliferation and invasion through inhibiting ALCAM in PAs. PAs is a common type of benign tumor of the central nervous system, but sometimes has aggressive behavior similar to malignant tumors [30]. Nowadays, the major diagnostic method is the imageology examination, and surgical treatment of pituitary tumors is the mainstream of traditional treatment methods. Aggressive initial PAs are difficult to resect completely, which often leads to tumor recrudescence [31]. Though little consensus about how invasive PAs constitute, the utility of biomarkers is rapidly evolving.

In general, one gene can be repressed by multiple miRNAs and one miRNA may repress multiple target genes, which results in the formation of complex regulatory networks [32]. miR-148 and miR-152 are in the same miRNA family and show the same seed sequence which is an important region for binding to mRNAs 3'UTR [17]. Theoretically, they target the same mRNA. Previous studies showed thatmiR-148/152 family can be the potential biomarkers in non-small-cell lung cancer and hepatocellular carcinoma [33, 34]. miR-148a, miR-148b, and miR-152 impair innate response and antigen presentation of TLR-triggered dendritic cells by targeting CaMKII $\alpha$ [35]. MiR-148b, miR-152 suppressed DNA methyltransferase-1 (DNMT1) gene in pancreatic cancer cell lines to be a tumor suppressor [36]. These studies showed that these miRNAs showed the same expression trends, targets and function. There're critical relevance of miR-148/152 family and cancer.

In this study, we detected that the expression level of miR-148b, miR-152 was lower in invasive pituitary adenoma patient cancer samples than noninvasive ones. miR-148/152 family can also be detected from serum [33]. Further, we found that miR-148b-3p, miR-152 expression level of PAs cell lines, GH3 and MMQ were significantly decreased compared with normal rat pituitary cells. So we used the GH3 and MMQ cell lines to mimic the PAs. Overexpression of miR-148b-3p and miR-152 could repress the proliferation and invasion of PAs cell lines. This result suggested that the downregulation of miR-148b-3p, miR-152 genes might be associated with the regulation of PAs growth, which suggested that miR-148b-3p, miR-152 might be the potential targets for further treatment for PAs. It is noticeable that miR-148b-3p and miR-152 played opposite roles in different cancers. In plasma, Cuk et al. noted that miR-148b was significantly upregulated in breast cancer patients [37]. Especially, the studies of Song et al. showed that miR-148b was downregulated in gastric cancer [38], colorectal cancer [19] and suppressed cell growth by targeting cholecystokinin-2 receptor(CCK2R). Differently, down-expression of miR-152 could lead to the impaired antitumor effect of killer cell in hepatocellular carcinoma via upregulation of HLA-G [39]. In endometrial cancer, Tsuruta et al. found miR-152 worked as a tumor suppressor silenced by DNA hypermethylation [40].

Targeted molecular therapeutics based on miRNAs hold great promise for the development of less toxic and more effective personalized treatment strategies for cancer [41]. The field of miRNAs is rapidly advancing toward in vivo delivery for therapeutic purposes. Interestingly, the bioinformatics also suggested that not only can in rat cells, miR148b-3p, miR-152 could also bind on the ALCAM mRNA 3'UTR in human beings (data not show). We will further detect the function of these miRNAs in human PAs. Several miR-148b, miR-152 direct target genes have been identified and experimentally confirmed in various studies $[19,35,38,42,43]$. Previous studies showed that miR-152 reduced invasion by targeting MMP3 in glioma [44]. miR-152 also suppressed migration and invasion through targeting FGF2 in NSCLC cell [45]. miR-148a promotes apoptosis of colorectal cancer by targeting Bcl-2 [46]. miR-152 represses the tumor growth of endometrial cancer [40]. miR$148 \mathrm{~b}$ regulated by BRG1inhibits proliferation and metastasis lung cancer [47]. These studies suggested the critical role of miR-148/152 family on regulating tumorigenesis.

We identified that ALCAM was a target of miR-148b-3p, miR-152 as well. This result suggested that miR-148b-3p and miR-152 provided epigenetic modulation on the level of ALCAM. ALCAM is a member of the cell surface immunoglobulin superfamily and is involved 
in homo- and heterophilic cell-cell interactions [48]. Previous study indicated strong cytoplasmic ALCAM expression was detected in aggressive breast cancer, possibly because ALCAM localize to the membrane to perform cell adhesion roles [49]. Actually, higher ALCAM expression is suggested to poor prognosis in various cancers [50, 51]. Here, we found a significant increase of ALCAM, as a direct consequence of reducing miRNAs. And the high expression of miR-148b-3p and miR-152 further repressed the expression of ALCAM, which led to the lower ability of invasion in PAs. These may also suggest the function of ALCAM to be the biomarker for clinical treatment. All these data were consistent with the phenomenon reported in the breast cancer [49]. Therefore, these findings suggest that in PAs cells miR148b-3p, miR-152/ ALCAM signaling axis play important role in regulating tumor growth.

\section{Conclusion}

MiR-148b-3p and miR-152 were low expressed in rat PAs and might serve as an antioncogene through repressing the proliferation and invasion by repressing ALCAM. Investigation on the function of miR-148b-3p, miR-152/ ALCAM signaling axis may lead to the novel therapeutic and diagnostic approaches for pituitary adenomas treatment.

\section{Acknowledgements}

This work was finacially supported by National Natural Science Foundation of China (no: 30760258), and Natural Science Foundation of Jiangxi Province (no: 20142BAB205032).

\section{Disclosure Statement}

The authors have declared that no Disclosure Statement exists.

\section{References}

1 Daly AF, Rixhon M, Adam C, Dempegioti A, Tichomirowa MA, Beckers A: High prevalence of pituitary adenomas: a cross-sectional study in the province of Liege, Belgium. J Clin Endocrinol Metab 2006;91:4769-4775.

- 2 Scheithauer BW, Kurtkaya-Yapicier O, Kovacs KT, Young WF, Jr., Lloyd RV: Pituitary carcinoma: a clinicopathological review. Neurosurgery 2005;56:1066-1074.

- 3 Ezzat S, Asa SL: Mechanisms of disease: The pathogenesis of pituitary tumors. Nat Clin Pract Endocrinol Metab 2006;2:220-230.

- 4 Shao S, Li X: Clinical features and analysis in 1385 Chinese patients with pituitary adenomas. J Neurosurg Sci 2013;57:267-275.

- 5 Herman V, Fagin J, Gonsky R, Kovacs K, Melmed S: Clonal origin of pituitary adenomas. J Clin Endocrinol Metab 1990;71:1427-1433.

6 6 Liu Q, Wang G, Chen Y, Li G, Yang D, Kang J: A miR-590/Acvr2a/Rad51b axis regulates DNA damage repair during mESC proliferation. Stem Cell Reports 2014;3:1103-1117.

7 Hu J, Chen C, Liu Q, Liu B, Song C, Zhu S, Wu C, Liu S, Yu H, Yao D, Kang J, Zhu L: The role of the miR-31/FIH1 pathway in TGF-beta-induced liver fibrosis. Clin Sci (Lond) 2015;129:305-317.

8 Seeliger C, Balmayor ER, van Griensven M: miRNAs related to skeletal diseases. Stem Cells Dev 2016;25.1261-1281.

- 9 Yan IK, Wang X, Asmann YW, Haga H, Patel T: Circulating Extracellular RNA Markers of Liver Regeneration. PLoS One 2016;11:e0155888. 


\section{Cellular Physiology Cell Physiol Biochem 2017;44:792-803 \begin{tabular}{l|l|l} 
and Biochemistry & Dublished online: November 24, 2017 & $\begin{array}{l}\text { (c) } 2017 \text { The Author(s). Published by S. Karger AG, Basel } \\
\text { www.karger.com/cpb }\end{array}$
\end{tabular}}

He et al.: MiR-148b, miR-152/AICAM Axis in Pituitary Adenomas

10 Duan B, Hu J, Zhang T, Luo X, Zhou Y, Liu S, Zhu L, Wu C, Liu W, Chen C, Gao H: miRNA-338-3p/CDK4 signaling pathway suppressed hepatic stellate cell activation and proliferation. BMC Gastroenterol 2017;17:12.

11 Wu W, Sun M, Zou GM, Chen J: MicroRNA and cancer: Current status and prospective. Int J Cancer 2007;120:953-960.

12 Shukla GC, Singh J, Barik S: MicroRNAs: Processing, Maturation, Target Recognition and Regulatory Functions. Mol Cell Pharmacol 2011;3:83-92.

13 Zhao G, Wang B, Liu Y, Zhang JG, Deng SC, Qin Q, Tian K, Li X, Zhu S, Niu Y, Gong Q Wang CY: miRNA-141, downregulated in pancreatic cancer, inhibits cell proliferation and invasion by directly targeting MAP4K4 Mol Cancer Ther 2013;12:2569-2580.

14 Gong J, Cui Z, Li L, Ma Q, Wang Q Gao Y, Sun H: MicroRNA-25 promotes gastric cancer proliferation, invasion, and migration by directly targeting F-box and WD-40 Domain Protein 7, FBXW7 Tumour Biol 2015;36:7831-7840.

15 Chai P, Tian J, Zhao D, Zhang H, Cui J, Ding K, Liu B: GSE1 negative regulation by miR-489-5p promotes breast cancer cell proliferation and invasion. Biochem Biophys Res Commun 2016;471:123-128.

16 Longqiu Y, Pengcheng L, Xuejie F, Peng Z: A miRNAs panel promotes the proliferation and invasion of colorectal cancer cells by targeting GABBR1 Cancer Med 2016;5:2022-2031.

17 Chen Y, Song YX, Wang ZN: The microRNA-148/152 family: multi-faceted players. Mol Cancer 2013;12:43.

18 Zheng B, Liang L, Wang C, Huang S, Cao X, Zha R, Liu L, Jia D, Tian Q, Wu J, Ye Y, Wang Q, Long Z, Zhou Y, Du C, He X, Shi Y: MicroRNA-148a suppresses tumor cell invasion and metastasis by downregulating ROCK1 in gastric cancer. Clin Cancer Res 2011;17:7574-7583.

19 Song Y, Xu Y, Wang Z, Chen Y, Yue Z, Gao P, Xing C, Xu H: MicroRNA-148b suppresses cell growth by targeting cholecystokinin-2 receptor in colorectal cancer. Int J Cancer 2012;131:1042-1051.

-20 Xu Q, Jiang Y, Yin Y, Li Q He J, Jing Y, Qi YT, Xu Q Li W, Lu B, Peiper SS, Jiang BH, Liu LZ: A regulatory circuit of miR-148a/152 and DNMT1 in modulating cell transformation and tumor angiogenesis through IGF-IR and IRS1 J Mol Cell Biol 2013;5:3-13.

-21 Zhou X, Zhao F, Wang ZN, Song YX, Chang H, Chiang Y, Xu HM: Altered expression of miR-152 and miR-148a in ovarian cancer is related to cell proliferation. Oncol Rep 2012;27:447-454.

-22 Wang R, Ye F, Zhen Q, Song T, Tan G, Chu W, Zhang Y, Lv B, Zhao X, Liu J: MicroRNA-148b is a potential prognostic biomarker and predictor of response to radiotherapy in non-small-cell lung cancer. J Physiol Biochem 2016;72:337-343.

23 Mou Z, Xu X, Dong M, Xu J: MicroRNA-148b Acts as a Tumor Suppressor in Cervical Cancer by Inducing G1/ S-Phase Cell Cycle Arrest and Apoptosis in a Caspase-3-Dependent Manner. Med Sci Monit 2016;22:28092815.

-24 van Kempen LC, van den Oord JJ, van Muijen GN, Weidle UH, Bloemers HP, Swart GW: Activated leukocyte cell adhesion molecule/CD166, a marker of tumor progression in primary malignant melanoma of the skin. Am J Pathol 2000;156:769-774.

-25 Donizy P, Zietek M, Halon A, Leskiewicz M, Kozyra C, Matkowski R: Prognostic significance of ALCAM (CD166/MEMD) expression in cutaneous melanoma patients. Diagn Pathol 2015;10:86.

-26 Poissonnier L, Villain G, Soncin F, Mattot V: miR126-5p repression of ALCAM and SetD5 in endothelial cells regulates leucocyte adhesion and transmigration. Cardiovasc Res 2014;102:436-447.

-27 Song Q, Xu Y, Yang C, Chen Z, Jia C, Chen J, Zhang Y, Lai P, Fan X, Zhou X, Lin J, Li M, Ma W, Luo S, Bai X: miR483-5p promotes invasion and metastasis of lung adenocarcinoma by targeting RhoGDI1 and ALCAM. Cancer Res 2014;74:3031-3042.

28 Ye M, Du YL, Nie YQ, Zhou ZW, Cao J, Li YF: Overexpression of activated leukocute cell adhesion molecule in gastric cancer is associated with advanced stages and poor prognosis and miR-9 deregulation. Mol Med Rep 2015;11:2004-2012.

29 Fukami K, Tasaka K, Mizuki J, Kasahara K, Masumoto N, Miyake A, Murata Y: Bihormonal cells secreting both prolactin and gonadotropins in normal rat pituitary cells. Endocr J 1997;44:819-826.

-30 Blevins LS, Jr., Verity DK, Allen G: Aggressive pituitary tumors. Oncology (Williston Park) 1998;12:13071312.

-31 Thapar K, Scheithauer BW, Kovacs K, Pernicone PJ, Laws ER, Jr:: p53 expression in pituitary adenomas and carcinomas: correlation with invasiveness and tumor growth fractions. Neurosurgery 1996;38:765-770. 


\section{Cellular Physiology Cell Physiol Biochem 2017;44:792-803 \begin{tabular}{l|l|l|l|} 
DOI: 10.1159/000485342 & O 2017 The Author(s). Published by S. Karger AG, Basel \\
wwww.karger.com/cpb
\end{tabular}

32 Xu N, Papagiannakopoulos T, Pan G, Thomson JA, Kosik KS: MicroRNA-145 regulates OCT4, SOX2, and KLF4 and represses pluripotency in human embryonic stem cells. Cell 2009;137:647-658.

-33 Wang F, Ying H, He B, Pan Y, Sun H, Wang S: Circulating miR-148/152 family as potential biomarkers in hepatocellular carcinoma. Tumour Biol 2016;37:4945-4953.

-34 Li L, Chen YY, Li SQ Huang C, Qin YZ: Expression of miR-148/152 family as potential biomarkers in nonsmall-cell lung cancer. Med Sci Monit 2015;21:1155-1161.

-35 Liu X, Zhan Z, Xu L, Ma F, Li D, Guo Z, Li N, Cao X: MicroRNA-148/152 impair innate response and antigen presentation of TLR-triggered dendritic cells by targeting CaMKIIalpha. J Immunol 2010;185:7244-7251.

-36 Azizi M, Teimoori-Toolabi L, Arzanani MK, Azadmanesh K, Fard-Esfahani P, Zeinali S: MicroRNA-148b and microRNA-152 reactivate tumor suppressor genes through suppression of DNA methyltransferase-1 gene in pancreatic cancer cell lines. Cancer Biol Ther 2014;15:419-427.

-37 Cuk K, Zucknick M, Heil J, Madhavan D, Schott S, Turchinovich A, Arlt D, Rath M, Sohn C, Benner A, Junkermann H, Schneeweiss A, Burwinkel B: Circulating microRNAs in plasma as early detection markers for breast cancer. Int J Cancer 2013;132:1602-1612.

-38 Song YX, Yue ZY, Wang ZN, Xu YY, Luo Y, Xu HM, Zhang X, Jiang L, Xing CZ, Zhang Y: MicroRNA-148b is frequently down-regulated in gastric cancer and acts as a tumor suppressor by inhibiting cell proliferation. Mol Cancer 2011;10:1.

39 Bian X, Si Y, Zhang M, Wei R, Yang X, Ren H, Zheng G, Wang C, Zhang Y: Down-expression of miR-152 lead to impaired anti-tumor effect of NK via upregulation of HLA-G. Tumour Biol 2016;37:3749-3756.

$>40$ Tsuruta T, Kozaki K, Uesugi A, Furuta M, Hirasawa A, Imoto I, Susumu N, Aoki D, Inazawa J: miR-152 is a tumor suppressor microRNA that is silenced by DNA hypermethylation in endometrial cancer. Cancer Res 2011;71:6450-6462.

41 Garofalo M, Croce CM: microRNAs: Master regulators as potential therapeutics in cancer. Annu Rev Pharmacol Toxicol 2011;51:25-43.

-42 Zhu XM, Han T, Wang XH, Li YH, Yang HG, Luo YN, Yin GW, Yao YQ: Overexpression of miR-152 leads to reduced expression of human leukocyte antigen- $\mathrm{G}$ and increased natural killer cell mediated cytolysis in JEG-3 cells. Am J Obstet Gynecol 2010;202:592.

43 Stumpel DJ, Schotte D, Lange-Turenhout EA, Schneider P, Seslija L, de Menezes RX, Marquez VE, Pieters R, den Boer ML, Stam RW: Hypermethylation of specific microRNA genes in MLL-rearranged infant acute lymphoblastic leukemia: major matters at a micro scale. Leukemia 2011;25:429-439.

44 Zheng X, Chopp M, Lu Y, Buller B, Jiang F: MiR-15b and miR-152 reduce glioma cell invasion and angiogenesis via NRP-2 and MMP-3 Cancer Lett 2013;329:146-154.

45 Su Y, Wang Y, Zhou H, Lei L, Xu L: MicroRNA-152 targets ADAM17 to suppress NSCLC progression. FEBS Lett 2014;588:1983-1988.

46 Zhang H, Li Y, Huang Q Ren X, Hu H, Sheng H, Lai M: MiR-148a promotes apoptosis by targeting Bcl-2 in colorectal cancer. Cell Death Differ 2011;18:1702-1710.

47 Zhou Z, Su Y, Fa X: Restoration of BRG1 inhibits proliferation and metastasis of lung cancer by regulating tumor suppressor miR-148b. Onco Targets Ther 2015;8:3603-3612.

48 Bowen MA, Aruffo AA, Bajorath J: Cell surface receptors and their ligands: in vitro analysis of CD6-CD166 interactions. Proteins 2000;40:420-428.

49 Burkhardt M, Mayordomo E, Winzer KJ, Fritzsche F, Gansukh T, Pahl S, Weichert W, Denkert C, Guski H, Dietel M, Kristiansen G: Cytoplasmic overexpression of ALCAM is prognostic of disease progression in breast cancer. J Clin Pathol 2006;59:403-409.

-50 Swart GW: Activated leukocyte cell adhesion molecule (CD166/ALCAM): developmental and mechanistic aspects of cell clustering and cell migration. Eur J Cell Biol 2002;81:313-321.

51 Weidle UH, Eggle D, Klostermann S, Swart GW: ALCAM/CD166: cancer-related issues. Cancer Genomics Proteomics 2010;7:231-243. 